\title{
Registration of Guta Barley (Hordeium vulgare L.) Variety for Bale Highlands
}

\author{
Ayalneh Tilahun, Zerihun Jalata* and Amare Biftu
}

Sinana Agricultural Research Center, P O Box 208, Bale-Robe, Ethiopia

\begin{abstract}
Guta is a common name for this barley (Hordeium vulgare L.) variety with a pedigree designation of Acc.3260-18. The variety has been developed and released by Sinana agricultural research center for commercial production in the highlands of Bale. It has been tested at Sinana, Agarfa, Robe and Adaba major barley growing areas during 2003-2005 years and showed better performances in grain yield over local variety, Aruso and standard variety, Shage. Thus, the variety has shown high mean grain yield and relatively stable across locations and years. It also showed comparable responses to net blotch, scald and barley leaf rust diseases as compared to Aruso, but it appears that Guta was less resistant to these barley diseases as compared to Shage may be due to its earliness. On the other hand, as observed during evaluation Guta possess resistance or tolerance to barley shoot fly insect than Shage; and exhibit compensatory growth after shootfly damage and these needs further research. The early maturing characteristics of the variety suits to the different cropping systems in the area and give better adoption potential by the local farmers.
\end{abstract}

Keywords: Guta; Barley (Hordeium vulgare L); Yield Performance; Early Maturity

\section{Introduction}

Guta (Acc.3260-18) barley (Hordeum vulgare L.) variety is food barley variety released in 2007 under Oromia Agricultural Research Institute by Sinana Agricultural Research Center. It was originally developed from Ethiopian barley landrace collections and selected by pure line selection methods at Sinana Agricultural Research Center (SARC) in barley landrace enhancement program to develop a variety with high yielding potential and other better agronomic traits. The material has been evaluated together with other genotypes in different breeding nurseries from 2000-2002 and then advanced to variety trial to see its varietal performance across locations and years in barley producing areas of Bale highland. The variety was officially released as commercial production in Bale highlands after approval by the Ethiopian National Variety Release Committee in accordance with the guidelines of the national variety release system and variety registration of the country. Breeder seed and foundation seed of the variety is maintained by SARC.

\section{Evaluation}

Guta (Acc.3260-18) was tested together with 20 barley genotypes including checks in regional variety trial at 12 environments in major barley producing areas in Bale highlands during 2003- 2005 consecutive years. Guta was evaluated along with Aruso and Shage as the local and standard variety, respectively at altitudinal range of 2400 3000 meter above sea level at Sinana, Agarfa, Adaba and Robe locations in each year. Since there is high shoot fly presence in these areas, the variety together with other genotypes and checks was checked frequently for shoot fly resistance or tolerance under natural condition at hot spot areas before advanced to variety trials (by visual observation) as shoot fly damage is easily identified and the effect is usually seen as stunt growth and reduced yield.

\section{Varietal Characteristics}

Guta is early maturing and six-rowed variety with erect growth habit. The variety matures with an average of 103 days which is more than two weeks earlier in maturity than the standard variety, Shage (Table 1) so that it can utilize moisture more efficiently. This short maturing habit is preferred by the local community as it can be produced efficiently with in the two main cropping seasons, Ganna (March-July) and Bona (AugustDecember). It is also characterized by better resistance/tolerance to main biological insect pest (shoot fly) than specially the standard variety (Shage) (visual observation); and showed rapid compensatory growth after damage by the insect. The variety is tall with average height of $93 \mathrm{~cm}$. The average days to heading and maturity is 58 and 103, respectively. On the other hand, seed color is grey and has average thousand-kernel weight of $33.2 \mathrm{~g}$ (Table 1).

\section{Yield and Stability Performance}

The results of the evaluation indicated important information regarding variety performance and stability. Thus, grain yield performance of the released barley variety and checks is described below in Table (1). During evaluation seasons, the overall location mean grain yield of this variety was better than all genotype means. Beside this, Guta was higher in mean grain yield over check varieties, exceeding by $21 \%$ and $4.5 \%$ over shage (standard variety) and Aruso (local variety), respectively. On research field Guta gave yield ranging from 2.4 to 4.9 t/ha, whereas 2.0 to $4.3 \mathrm{t} / \mathrm{ha}$ on farmers' field. In addition, stability analysis was done on grain yield using three years (2003-2005) data. According to joint regression model, a variety with high mean yield, regression coefficient (bi) of unity and with deviation from regression $\left(\mathrm{S}^{2} \mathrm{di}\right)=0$ is stable (Eberhart and Russell, 1966). In this regard, Guta is stable variety with high mean grain yield, regression coefficient (bi) of 1.07 which is nearly unity and deviation from regression of 0.02 which is equivalent to zero. Therefore, it has shown stable yield performance across locations of evaluation as well as higher mean grain yield over check varieties (Shage and Aruso). 


\section{Disease Reaction}

Data recording was done for all genotypes including this variety for major barley diseases such as net blotch (Pyrenophora teres Drechs.), scald (Rhynchosporium secalis Oud.) and barley leaf rust (Puccinia hordei Otth) at across all environments (Table 1). Data was taken at 51-69 plant growth stages (Zadoks et al., 1974) across locations. Both diseases, net blotch and scald were scored using 00-99 double digit scale (Saari and Prescot,1975) in such a way that the first digit indicate the spread of disease in a plot ( $\%$ incidence) and the second digit indicate the percentage of leaf area infected ( $\%$ severity),i.e $1=<10 \%, 2=10$ $20 \%, 3=20-30 \%, 4=30-40 \%, 5=40-50 \%, 6=50-60 \%$, $7=60-70 \%, 8=70-80 \%$ and $9=>80 \%$. Whereas, barley leaf rust data was collected based on Stubs et al.(1986) methodology. Thus, it was observed that the disease responses of the early maturing candidate variety (Guta) to the above three diseases was comparable with local (Arsuo) variety; however, it appears that Guta was less resistant to these major barley diseases as compared to Shage (standard variety) which is late maturing type. Similarily, Parlevliet and Moseman (1986) and Getaneh et al.(1999) indicated in their reports as early maturing barley lines showed less resistance to leaf rust than late types. And, Yitbarek et al. (1998) also found early maturing barley populations as less resistant to net bloch and scald disease due to escaping mechanisms by late maturing types. Michael et al. (1989) reported positive relationship between earliness and grain yield.

\section{Farmers Evaluation of the Variety}

To evaluate the perception and preferences of the local farmers, farmers' participatory barley variety evaluation and selection was conducted at five representative sites in Bale highlands during 2007 Bona cropping season. Farmers made selection and evaluation individually and in-group. In this evaluation, 12 released varieties were included together with Guta. Among the best barley varieties ranked from one to four during selection is presented in Table 2. in this regard, Guta was almost selected or ranked as first variety preferred by the local farmers mainly due to its yield performance, early maturity, productive tillers and relatively disease free than other varieties tested.

\section{Adaptation}

Guta variety is recommended for production in the highlands of Bale with annual rainfall of about $590 \mathrm{~mm}$ in the Ganna and $560 \mathrm{~mm}$ in Bona season (Hailu et al., 1996). Nevertheless, the variety can be adapted to other regions or areas with similar agro-ecologies through adaptation. It can best suit to the two main growing seasons in the area due to its early maturity and suitable in a sense that harvesting of the variety in the Ganna season could be followed by planting pulse crops during the Bona as rotation. On black soils, $50 \mathrm{~kg}$ DAP (diammonium phosphate) fertilizer is recommended to give good yield and with $125 \mathrm{~kg}$ seed rate. In addition, the variety can be planted early March for Ganna season and early August for Bona season.

Table 1. Overall mean grain yield, other important agronomic traits and disease reaction of Guta (Acc.3260-18) barley variety and checks across locations and years.

\begin{tabular}{|c|c|c|c|c|c|c|c|c|c|c|c|}
\hline No. & Variety & $\begin{array}{l}\text { Row } \\
\text { type }\end{array}$ & $\mathrm{DH}$ & $\mathrm{DM}$ & $\begin{array}{l}\mathrm{PH} \\
(\mathrm{cm})\end{array}$ & $\begin{array}{l}\text { TKW } \\
\text { (gm) }\end{array}$ & $\begin{array}{l}\text { HLW } \\
(\mathrm{kg} / \mathrm{hl})\end{array}$ & $\begin{array}{l}\text { NB } \\
(00-99)\end{array}$ & $\begin{array}{l}\text { Scald } \\
(00-99)\end{array}$ & $\begin{array}{c}\text { LR } \\
\text { (Rxn) }\end{array}$ & $\begin{array}{c}\text { GY } \\
\text { (t/ha) }\end{array}$ \\
\hline 1 & Acc.3260-18 & six & 58 & 103 & 93 & 33.2 & 61.6 & 83 & 82 & $40 \mathrm{MS}$ & 2.3 \\
\hline 2 & Aruso (L. Vty) & irreg. & 61 & 107 & 92 & 35.1 & 62 & 80 & 82 & $40 \mathrm{MS}$ & 2.2 \\
\hline 3 & Shage (St.Vty) & six & 67 & 119 & 88 & 35.5 & 60 & 61 & 61 & $5 \mathrm{MS}$ & 1.9 \\
\hline
\end{tabular}

DH=Days to heading, DM=Days to maturity, PH=Plant height, TKW=Thousand kernel weight, NB=Net Blotch, LR =Leaf Rust, $\mathrm{R} \times n=$ Reaction, $H L W=$ hectoliter weight, $\mathrm{kg} / \mathrm{hl}=$ Kilogram hectoliter ${ }^{-1}, \mathrm{t} / \mathrm{ha}=$ ton hectare ${ }^{-1}$, irreg. =irregular, St.Vty=standard variety, L.V ty=local variety \& $G Y=$ Grain Yield.

Table 2. Farmers' rankings of best barley varieties at different five sites in Bale highlands.

\begin{tabular}{llllll}
\hline Variety & Sites & & & \\
\cline { 2 - 6 } Guta & Salka IV & Salka III & Salka II & Ilani & Rataba \\
Dinsho & $2(2)$ & $1(1)$ & $1(1)$ & $1(1)$ & 1 \\
Biftu & 3 & $3(2)$ & - & $3(2)$ & 4 \\
Harbu & 4 & 4 & 4 & $2(3)$ & 2 \\
Dafo & $(3)$ & 2 & $2(2)$ & $4(4)$ & 3 \\
Meserach & - & $5(3)$ & 3 & - & - \\
\hline
\end{tabular}

The number in the parenthesis indicate the rank given by farmers in group selection

\section{Acknowledgment}

The authors would like to thank the Oromia Agricultural Research Institute, Sinana Agricultural Research Center for financing and providing working facility in developing the variety. Moreover, we acknowledge Bedada Legesse, Dessalegn Lemma, Dame Niguse, Tesfaye Tadesse, Gezahegn Tadesse for their assistance in field data collection. 


\section{Reference}

Eberhart, S.A. and Russell, W.A. 1966. Stability parameters for comparing varieties. Crop Science 6:36-40.

Getaneh, W., Fekadu, A., Bekele, H. and Melkamu, A. 1999. Evaluation of barley germplasm for resistance to barley leaf rust (Puccinia hordei Otth).Pest Management Jornal of Ethiopia. Vol.3 (1 and 2):39-45.

Hailu, G., Berhane, L., Fekadu, F., Behanu, B., Alemayehu, A. and Tesfaye G. 1996. Food barley breeding. In: Hailu, G. and Joop, V.L. (eds.). Barley Research in Ethiopia. Past Work and Future Prospects. Proceedings of the First Barley Research Review Workshop, 16-19 Oct. 1993, IAR/ICARDA, Addis Abeba, Ethiopia. pp.9-23.

Michael, J., Gustave, M. and Darek, R. 1989. The agrometeorology of rainfed barley based farming system. Proc. of an international Symposium 6-10 march, 1989, Tunis. pp. 35-58.

Parlevliet, J.E. and Moseman, J.G. 1986. Inventory of Ethiopian barley lines for resistance to barley leaf rust. Cereal rust bulletin.Vol.14, Part I. pp.1-6.

Saari, E.E. and Prescott, J.M. 1975. A scale for appraising the foliar intensity of wheat diseases. Plant Diseases 59: 377-380.

Yitbarek, S., Berhane, L., Fikadu, A., Van Leur, J.A.G., Grando, S. and Ceccarelli, S. 1998. Variation in Ethiopian barley populations for resistance to barley leaf scald and netblotch. Plant Breeding 117:419-423.

Zadoks, J.C., Chang, T.T. and Konzak, C.F. 1974. A decimal code for the growth stages of cereals. Weed Research 14:415-421. 